\title{
Teaching Preschoolers to Self-Assess Their Choices in Pre-K
}

\author{
Bobbie Gibson Warash \\ West Virginia University \\ Melissa Workman \\ West Virginia University
}

\begin{abstract}
Young children have the capability of making decisions, informed choices, and self-assessing their progress on their choices. In this classroom of 4- and 5-year-olds, children used pictorial contracts, rubrics, and various self-assessment techniques as a method for continuous learning. Gathering and reflecting on their own evidence about their accomplishments created a reflective loop by which the child evaluated their work, made revisions and ultimately applied the criteria to other conditions. Children in this prekindergarten classroom learned to reflect on their own knowledge. It is not only intrinsically motivating but offers young children a systematic approach to further their involvement in their learning in a developmentally appropriate and engaging environment.
\end{abstract}

Keywords: self-assessment, rubrics, early childhood, pre-k

\section{Introduction}

Developmentally, preschoolers are in a stage of development that stresses the preoccupation about themselves. A young child's self-centeredness is a characteristic of this period, which Piaget (1970) called the preoperational stage of development. Piaget believed children lacked the ability to process logical thought because of the aspect of centration, focusing on one facet of a situation to the exclusion of others. Children view the world from their perspective. Piaget summarized that children demonstrate their egocentricity through their speech as they often engage in talking to themselves, especially as they play. This type of self-talk was viewed differently by Vygotsky (1978) who thought it was more beneficial to the growth of a child's social speech as well as their cognitive development.

Understanding the realm of young children's development but not limited by its parameters, the authors of this article have developed classroom strategies that utilize the young child's characteristic of self-absorption and propensity towards self-talk to enhance their learning experiences and self-regulation skills. Both authors are child development specialists in a university laboratory prekindergarten (pre-k) classroom and have established practices grounded from their own action research (Warash, 2011; Warash, et al., 2013; Warash, Smith, \& Root, 2011) as well as the influences of established educational researchers (Bailey \& Jakicic, 2012; Hattie, 2012). The purpose of this paper is to share insights of giving young children the opportunity to be involved in decisions about their own learning as well as evaluating their own progress. Children are capable of reflecting on their learning (Hattie, 2012), and teachers of young children need not be hesitant to set these expectations. The young child's developmental characteristic of self-absorption and self-talk is the platform from which these strategies were designed.

Some of the early influences of young children being involved in their own learning through selfassessing their progress emanates from the research of Moxley, Kenny, and Hunt (1990) and Moxley 
and Studwell (1994) with a more recent impact from the research of Hattie (2012). Moxley et al. theorized that in lieu of relying on the traditional approach of teachers making comments and grading, children could take the role of evaluating their own progress. Their research specifically related this self-assessment approach to writing development but suggested it could be used in various academic situations. When children comment on their own work, it gives them the basis to review, compare, revise, and engage in further approximation to conventionality. Moxley et al. implied there are obvious limitations to solely using teacher evaluations and comments as it creates a cycle that children try something then wait for the teachers to respond. Waiting for commentaries or superficial comments such as "good job" does not allow the child to expand their involvement or efforts. Children need appropriate feedback immediately in order for it to be the most effective. We believe that offering experiences where children review their work allows them to build selfevaluation skills needed to consider progress within the task; subsequently serving to motivate them to put more effort into their work and ultimately assists them in becoming involved in their learning.

Four- and 5-year-olds in our university pre-k classroom are taught to review and reflect on their work as well as their play. It becomes part of their daily process whether they are building a block structure or printing their name. One noted example in our pre-k class was Tracy, a 4-year-old who assessed her printing when she said she could have done better on printing her name but she messed up on the letters. She decided to try it again. Her own review coupled with her second effort demonstrated her self-acknowledgement and persistence. A child who is working hard to print letters may not have the letters formed orthodoxly but it is the sustained interest and attempts that needs to be acknowledged. Encouraging young children to critique or assess their own work (Moxley et al., 1990) while the teacher acknowledges the effort gives children more control of their success (Dweck, 2007). Having young children participate in their own evaluation also aligns with the expectations of the national teacher performance assessment developed at the Stanford Center for Assessment, Learning, and Equity (2016). One of the criteria of this assessment is to measure the teacher's effectiveness in involving young children in their own learning.

The question is, "How can early childhood teachers help young children be involved in making decisions about their own learning goals and assess their progress that is congruent with the child's stage of development?" Wilson and Conyers (2013), in their book, Flourishing in the First Five Years, stressed that with adult guidance, young children can develop self-control and learn to be critical thinkers. Self-control enables children to organize and accomplish goals and helps to establish the executive functions needed for lifelong learning (Goldberg, 2009). Florez (2011) reiterated that one of the most efficient ways for young children to build self-regulation and executive function is for teachers to scaffold these skills during the daily activities so it becomes routine and is practiced. The various strategies used in our university pre-k classroom help young children become more cognizant of their intentions whether in play or a more formal academic activity. These strategies were developed within the boundaries of respecting the young child's cognitive stage of development as based on theories of Piaget (1970) and Vygotsky (1978).

\section{Strategies Promoting Children's Involvement in Their Own Learning}

\section{Strategy One: Planning Play}

Many preschools and kindergartens use play plans or some type of journaling system. One of the most prominent methods is High Scope's use of Plan, Do, and Review (Epstein, 2008). Just as the name implies, children make a plan, and once they make progress with their plans, they review their work with the teacher. In our pre-k class, children use a similar method of discussing their plans for 
play with the teacher and proceed to draw, pretend print or print their ideas in their play plan notebooks. Leong and Bedrova (2012) emphasized the importance of children planning play but specified that the benefit is expanded when young children draw and write their thoughts on paper. According to Leong and Bedrova, this increases the child's commitment to their plans. In our pre-k class, good decision making is practiced with the use of play plans. Children are not only engaged in conversations about their decision, but they are representing their thoughts in a notebook. To facilitate the possibilities for play choices, our pre-k classroom uses a one-page chart with pictorial icons representing the different options and interest areas of the classroom so children have a reference for planning. It has been observed prior to the use of plan plans in our pre-k class when there was no systematic approach to choosing activities, children typically walked around until they come to the first area that appealed to them but to the exclusion of knowing other options. Children need to know the possibilities before they can intentionally make a decision among the available choices (Warash et al., 2013).

The use of daily play plans has functioned not only as catalyst for children making and talking about their decisions but has also demonstrated their advances in literacy development. Bedrova and Leong (2007) termed the phrase "scaffolding writing" by using the theory of Vygotsky (1978) as the basis of this teaching strategy of planning play and representing those plans through drawing and writing. Their research has demonstrated that coupling play plans and pretend play produces optimal benefits because children are drawing, writing, and thinking about the details of their plan. Having children think about what they doing, evaluating, and editing their own work brings further involvement and the opportunity for additional and meaningful learning (Warash et al., 2011). In our pre-k class, some children request the teacher to write their dictations about their drawings in their play plans while other children do their own pretend writing. Some children want to copy or trace the teachers print while others try their own invented spelling.

\section{Strategy Two: Pictorial Contracts}

Play plans help children to make decisions during free play time by letting them know the possibilities, while contracts help them to make decisions among the teacher directed activities. Empowering children to methodically pick an activity that is visually represented encourages thinking before doing (Warash, 2001). Each day, children are given a contract with small pictorial icons on the left side of the paper representing the teacher planned activity. These teacher-planned activities align with the specific objectives of the required state content standards. Children choose the activity they want to do first by reviewing the options on the contract. Children take charge of placing a mark on the contract to the corresponding icon when they have completed the activity. Children rotate themselves to the various activities. Contracts give children the control of deciding when to move to another activity so they are not dependent on a teacher to move them. Reviewing their contracts at the end of the day in a large group meeting with the teacher further empowers young children to reflect and share their accomplishments. This approach differs from Plan, Do and Review of High Scope (Epstein, 2008), in that children are picking from the available teacher planned activities. Taking contracts home each day gives further opportunities for parent/child discussions and rich conversations about their learning. Some parents have commented that their children like to keep a notebook of their daily contracts and refer to them quite often, especially when they play school.

The pictorial contract gives children flexibility to not only make decisions about what teacher directed activity to do first but also the length of time they commit to an activity. Some children move at a steady pace through the available activities on the contract while others become more focused on a particular activity. When a student teacher or teacher is not available to conduct the 
planned activity, the teacher makes the activity a child-directed center. In essence, there are approximately five or six activities conducted at the same time and are represented on the contract. This democratic design of the classroom exemplifies children's ability to make decisions and set their own pace for completion. Pictorial contracts compliment the play plans.

\section{Strategy Three: Goal Setting}

In addition to contracts and play plans, children and the teacher determine a specific goal for the child to accomplish over a school semester. Some children pick an academic goal associated with reading or writing while others choose a topic. For example, 4-year-old Drew wanted to learn his home phone number while Liam wanted to learn everything he could about penguins. Young children deciding a goal was the focus of a single case design study in this pre-k classroom with the researchers concluding that young children can determine an appropriate goal (Warash et al., 2011). Once a goal is determined, the child and the teacher decide the specific steps or targets in reaching that goal. The incremental targeted steps are written on paper for the child and referred to when the child and teacher work on the goal. As a child accomplishes a step, the child records progress by putting his/her initial by the accomplished step.

David, a 4-year-old child in our pre-k class, picked his grandpa to study. His grandpa was a coal miner and David was fascinated with the lunch pail his grandpa used in the coal mines. He decided to make his own version of the lunch pail from recyclables. David and the teacher developed a plan of action with the incremental steps of making a replica of the lunch pail. The incremental steps were represented on a chart. David with the help of the teacher researched the topic and developed questions to ask his family before he began his construction of the pail. Other children became interested in the process of making the lunch pail, so children observing began conversations with David. This adds to the richness of the project. Once the lunch pail was completed, David made a presentation in large group meeting about the lunch pail he constructed. Again, this approach of involving the children in their own learning expectations sets a precedent for children to take a responsibility in their own inquiry even at age 4 .

The significant feat of this goal setting project is children keep their own record of progress with the assistance of the teacher. Wilson and Conyers (2013) reiterated that the step by step process helps children realize they can reach the large goal. Children self-recording their progress provides for individualized instruction where each child's progress along with the conditions for the child's success are evaluated in terms of the child's accomplishments (Moxley \& Studwell, 1994). Selfrecording their own progress on reaching the goal also strengthens a child's literacy skills. Wilson and Conyers said most children are not naturally metacognitive, but all students, from struggling learners to high performers, can benefit from being taught how and when to use a variety of cognitive strategies to monitor and improve their learning. Essentially children in this classroom are deciding a goal, planning how to reach the goal, and assessing their own progress towards the goal. This is an effective metacognitive approach for young children.

\section{Strategy Four: Long-Term Projects}

Katz and Chard (2000) have emphasized benefits of project work with young children because children have the chance to pursue their own questions and investigations and make their own decisions. The use of long-term projects works well in the philosophy of our pre-k classroom. Project work aligns with the use of pictorial contracts, play plans, and the child determining a goal. All of these strategies defined above encourage involvement of the child in their learning. Long-term projects provide for flexibility for the child to make decisions of commitment. They offer children 
opportunities to gauge their involvement and pursue their own interests. Project topics vary in this pre-k class but often times the child's interests and questions form the basis for project work. Recently, several children in our pre-k studied pumpkins because of their interest in planting a garden. In our pre-k we have found that when children are given opportunities to plan, monitor their work, direct their own learning, and self-reflect, student ownership increases (Warash, Smith, \& Root, 2011).

\section{Strategy Five: Rubrics}

The successful use of plan plans, contracts, and goal setting was the precursor to the implementation of simple rubrics for young children to have a visible way to assess their progress. Hattie (2012) discussed visible teaching and learning as being clear with challenging goals that the children and teacher work together to decide if the goal has been met. The rubrics in this pre-k class were designed for children to assess their progress by giving them a tool for critiquing their own work. The children had already incorporated advanced organizers through the use of play plans and pictorial contracts so the next logical step was to encourage children to be more intentional about evaluating their work. To do this, a simple rubric system was designed to craft a relationship between intention and effort. Initially, the rubrics were launched within activities associated with language arts but quickly they permeated to other academic areas of the classroom. With little coaching, children quickly became natural critics of their own work and effort using this tool and principle.

Pre-k children in this classroom quickly assimilated the rubric concept. They were taught to apply the criteria of " 1 " meaning minimal effort, " 3 " indicating good effort, and " 5 " suggesting it was the best work ever. However, children began incorporating the use of the established rubric criteria not only on written work samples, but on their classroom behaviors and play. For example, Amy had challenges leaving school when her parents arrived. She wanted to stay longer. The teacher asked Amy to use the rubric criteria and think about what would constitute a " 1 ", " 3 " and " 5 " in relation to leaving school. Amy stated that a "1" would be a child who was crying, not listening to their parents and throwing a fit. Dialogue progressed towards a " 3 " and ultimately a " 5 " which would consist of cleaning up, saying goodbye to friends, greeting their parents, and walking out the door willingly. During this self-assessment opportunity Amy reflected on the quality of her behavior using the rubric as a reminder and a graphic organizer.

Children's self-evaluations using the rubric tool demonstrated timely and specific commentary on their learning and achievements. Teachers in our pre-k class believe children had the capacity to evaluate their work with intentional guidance from teachers without a value judgement of failure. Teachers encouraged children to focus their authentic learning using this rating system but did not judge their evaluations. They respected children's verbal assessments while knowing best practice suggests giving them time for revision and application of new ideas within their work. Instructional leaders strive for creation of this type of feedback loop (Taylor, 2015; Wiggins, 2012).

The use of simple rubrics facilitated the notion of young children owning the process of evaluation. These young children drove the process of self-assessment and took the concept beyond what teachers intended. Parents reported using the system at home as it related to chores, cooperation, routines, and use of good manners. Extending the use of self-assessment at home empowered children and minimized the constant negotiating practices of children to get what they want. Children came to school reporting how well they made their bed, picked up their toys, carried groceries in from the car, and used their manners at dinner. 
Introducing rubrics with pre-k learners established and reinforced a culture within the classroom where children were not simply praised for a "good job" but commended for their perseverance, determination, and their ability to focus. Teachers created a cultural shift where high expectations for learning were provided by giving children the strategies to take a role in their own learning. The goal of coaching students to self-assess, support their findings, and scaffold them toward a new level of performance was achieved through the use of rubrics in our pre-k classroom.

Bailey and Jakicic (2012) recognized that when students and teachers work together to score themselves on a rubric, the rubric becomes part of the learning and it is not just a way to measure the learning. For these young children, the dialogue and feedback between them and the teacher inspired effort. Children are eager to share their comments and, as Hattie (2009) suggested, feedback from the student to the teacher is powerful. Specific feedback that is informative on the processes children used to complete the task promotes their ability to self-regulate their own learning and extend executive functions. Teachers need to eradicate general feedback such as "well done" or "good job" and use relevant vocabulary of the task. Katz and Katz (2009) reiterated that the intellectual content in the interactions with children needs to be rich and not merely on the established schedule, but rather, children should have opportunities to evaluate their own progress.

\section{Final Thoughts}

According to Piaget (1970), preschoolers are in the preoperational stage of development and consequently their thinking is more concrete. However, this should not limit the expectations of the early childhood teacher. Academics for preschoolers are more than alphabet and numbers as child development experts emphasize that one crucial piece for preschoolers to be successful in kindergarten requires self-regulation skills (Lin, Lawrence, \& Gorrell, 2003). Although young children are said not to possess the cognitive capabilities to discern thinking about thinking, they can certainly begin the more tangible processes to build skills for initial metacognition. Research shows that metacognitive skills can be taught to students to improve their learning (Nietfeld \& Schraw, 2002; Thiede, Anderson, \& Therriault, 2003). Shayer (2003) asserted the mind grows when exposed to challenge and cognitive conflict, which is a necessary component for the process of learning. Having children involved in their own learning and evaluation creates a disequilibrium where teachers can scaffold the child to a higher level. According to Hattie (2012), teaching requires deliberate interventions to make sure there is cognitive change.

James Heckman (2013), an economist from the University of Chicago and Noble Laureate, said that the non-cognitive skills that emerge in early childhood are among the strongest indicator of adult outcomes. Such qualities of persistence and curiosity play a crucial role. The way to support these skills is associated with helping children feel in control of their learning process. Encouraging children to not only plan and monitor their progress, but also collaborate and reflect on the strategies they use in their play and work assists in building skills for lifelong learners. Pre-k teachers can intentionally guide young children to make informed decisions through the child's own planning, setting of goals, and assessing their progress in an environment conducive to learning. 


\section{References}

Bailey, K., \& Jakicic, C. (2012). Common formative assessment. Bloomington, IN: Solution Tree Press.

Bodrova, E., \& Leong, D. J. (2007). Tools of the mind: The Vygotskian approach to early childhood education. Upper Saddle River, NJ: Pearson Prentice Hall.

Dweck, C. S. (2007). The perils and promise of praise. Educational Leadership. 65, 34-39.

Epstein, A. S. (2008). Teaching students to think: An early start on thinking. Educational Leadership, 65, 38-42.

Florez, I. R. (2011). Developing young children's self-regulation through everyday experiences. Young Children, 66, 46-51.

Goldberg, E. (2009). The new executive brain: Frontal lobes in a complex world. New York, NY: Oxford University Press.

Hattie, J. (2012). Visible learning for teachers: Maximizing impact on learning. London, United Kingdom: Routledge.

Heckman, J. (2013). Giving kids a fair chance. Cambridge, MA: MIT Press.

Katz, L. G., \& Chard, S. C. (2000). Engaging children's minds: The project approach (2nd ed). Stamford, CT: Ablex.

Katz, L. G., \& Katz, S. J. (2009). Intellectual emergencies: Some reflections on mothering and teaching. Lewisville, NC: K Press.

Leong, D., \& Bedrova, E. (2012). Assessing and scaffolding make-believe play. Young Children, 67, $28-34$.

Lin, H., Lawrence, F. R., \& Gorrell, J. (2003). Kindergarten teachers' views on children's readiness for school. Early Childhood Research Quarterly, 18, 225-237.

Moxley, R. A., Kenny, K. A., \& Hunt, M. K. (1990). Improving the instruction of young children with self-recording and discussion. Early Childhood Research Quarterly, 5, 233-249.

Moxley, R. A., \& Studwell, P. (1994). Self-recording in kindergarten: A study in naturalistic evaluation. Psychology in the Schools, 21, 450-456.

Nietfeld, J. L., \& Schraw, G. (2002). The effect of knowledge and strategy explanation on monitoring accuracy. Journal of Educational Research, 95, 131-142.

Piaget, J. (1970). The conception of time. New York, NY: Basic Books.

Shayer, M. (2003). Not just Piaget; not just Vygotsky, and certainly not Vygotsky as alternative to Piaget. Learning and Instruction, 13, 465-485.

Stanford Center for Assessment, Learning, and Equity. (2016). edTPA early childhood assessment handbook. Amherst, MA: Pearson.

Taylor, M. (2015). Starting student feedback loops (Resource document). Retrieved from http://www.edutopia.org/blog/starting-student-feedback-loops-taylor-meredith

Thiede, K. W., Anderson, M. C., \& Therriault, D. (2003). Accuracy of metacognitive monitoring affects learning of texts. Journal of Educational Psychology, 95, 66-73.

Vygotsky, L. (1978). Mind and society: The development of higher mental process. Cambridge, MA: Harvard University Press. 
Warash, B. (2001). Is it contract day? Focus on Pre-K \& K, 13, 4-7.

Warash, B., Day, J., Workman, M., Trollo, J., Law, K., \& Devito, M. (2013). History invades the preschool classroom. Journal of Modern Education Review, 3, 478-484.

Warash, B., Smith, K., \& Root, A. (2011). "I want to learn my phone number": Encourage young children to set their own learning goals. Dimensions of Early Childhood, 39, 12-19.

Wiggins, G. (2012). Feedback for learning: Seven keys to effective feedback. Educational Leadership, $70,10-16$.

Wilson, D., \& Conyers, M. (2013). Flourishing in the first five years. Lanham, MD: Rowman \& Littlefield.

The Journal of Educational Research and Practice provides a forum for studies and dialogue that allows readers to better develop social change in the field of education and learning. Journal content may focus on educational issues of all ages and in all settings. It also presents peer-reviewed commentaries, book reviews, interviews of prominent individuals, and additional content. The objectives: We publish research and related content that examines current relevant educational issues and processes aimed at presenting readers with knowledge and showing how that knowledge can be used to impact social change in educational or learning environments. Additional content provides an opportunity for scholarly and professional dialogue regarding that content's usefulness in expanding the body of scholarly knowledge and increasing readers' effectiveness as educators. The journal also focuses on facilitating the activities of both researcher-practitioners and practitioner-researchers, providing optimal opportunities for interdisciplinary and collaborative thought through blogging and other communications.

Walden University Publishing: http://www.publishing.waldenu.edu 